\title{
Impact of statin therapy on mortality in patients with sepsis-associated acute respiratory distress syndrome (ARDS) depends on ARDS severity: a prospective observational cohort study
}

\author{
Ashham Mansur ${ }^{1 *}$, Maximilian Steinau ${ }^{1}$, Aron Frederik Popov², Michael Ghadimi ${ }^{3}$, Tim Beissbarth ${ }^{4}$, \\ Martin Bauer ${ }^{1}$ and José Hinz ${ }^{1}$
}

\begin{abstract}
Background: Previous investigations have presumed a potential therapeutic effect of statin therapy in patients with acute respiratory distress syndrome (ARDS). Statins are expected to attenuate inflammation in the lungs of patients with ARDS due to their anti-inflammatory effects. Clinical investigations of the role of statin therapy have revealed contradictory results. This study aimed to investigate whether pretreatment and continuous therapy with statins in patients with sepsis-associated ARDS are associated with 28-day survival according to disease severity (mild, moderate, or severe).

Methods: Patients with sepsis-associated ARDS from the surgical intensive care were enrolled in this prospective observational investigation. ARDS was classified into three groups (mild, moderate, and severe); 28-day mortality was recorded as the primary outcome variable and organ failure was recorded as secondary outcome variable. Sequential Organ Failure Assessment scores and the requirements for organ support were evaluated throughout the observational period to assess organ failure.

Results: 404 patients with sepsis-associated ARDS were enrolled in this investigation. The distribution of the ARDS subgroups was $13 \%, 59 \%$, and $28 \%$ for mild, moderate, and severe disease, respectively. Statin therapy improved 28-day survival exclusively in the patients with severe ARDS compared with patients without statin therapy $(88.5 \%$ and $62.5 \%$, respectively; $P=0.0193$ ). To exclude the effects of several confounders, we performed multivariate Cox regression analysis, which showed that statin therapy remained a significant covariate for mortality (hazard ratio, 5.46; $95 \% \mathrm{Cl}, 1.38-21.70 ; P=0.0156$ ). Moreover, after carrying a propensity score-matching in the severe ARDS cohort, Kaplan-Meier survival analysis confirmed the improved 28-day survival among patients with statin therapy $(P=0.0205)$. Patients with severe ARDS who received statin therapy had significantly more vasopressor-free days compared with those without statin therapy ( $13 \pm 7$ and $9 \pm 7$, respectively; $P=0.0034$ ), and they also required less extracorporeal membrane oxygenation (ECMO) therapy and had more ECMO-free days (18 \pm 9 and $15 \pm 9$, respectively; $P=0.0873$.
\end{abstract}

Conclusions: This investigation suggests a beneficial effect of continuous statin therapy in patients with severe sepsis-associated ARDS and a history of prior statin therapy. Further study is warranted to elucidate this potential effect.

Keywords: 3-hydroxy-3-methylglutaryl CoA reductase inhibitor, 28-day survival, Acute respiratory distress syndrome, Intensive care unit, Statins

\footnotetext{
* Correspondence: ashham.mansur@med.uni-goettingen.de

'Department of Anesthesiology, University Medical Center, Georg August

University, D-37075 Goettingen, Germany

Full list of author information is available at the end of the article
} 


\section{Background}

Despite improvements in supportive treatment for acute respiratory distress syndrome (ARDS), mortality among patients with sepsis-associated ARDS remains high [1]. The pathogenesis of this syndrome is characterized by overwhelming inflammation that results in alveolar damage, accompanied by the exudation of protein-rich pulmonary-edema fluid in the alveolar space, which leads to respiratory failure [2]. During the course of this inflammation, which results in cellular damage and death, the development of both pulmonary and extra-pulmonary organ failure is promoted. Consequently, therapies that attenuate inflammation may have positive impacts on the clinical course and outcome of patients with ARDS [3]. Inhibitors of 3-hydroxy-3-methylglutaryl coenzyme A reductase, known as statins, are frequently prescribed for treatment of hypercholesterolemia worldwide. However, statins also have immunosuppressive properties and can attenuate inflammation. In ARDS murine models, statins have been shown to prevent disease development $[4,5]$. Simvastatin, which is among the most prescribed statins worldwide, has been shown to reduce pulmonary and systemic inflammatory responses in a human model of ARDS induced by lipopolysaccharide inhalation [6]. Whereas several studies have suggested that patients with severe inflammatory conditions, such as sepsis or ARDS, who receive statins have improved clinical outcomes [4, 6-10], other studies examining the impacts of statin therapy on the clinical outcomes of these patients have failed to show any beneficial effects [11-13]. These contradictory results regarding the beneficial impacts of statin therapy on ARDS patients might be due to the fact that the previous studies evaluated heterogenic ARDS patient groups without considering disease severity as a potential determinant of therapeutic responsiveness.

According to the Berlin definition of ARDS [14], disease severity can be classified based on the degree of arterial hypoxemia, as indicated by the $\mathrm{P}_{\mathrm{a}} \mathrm{O}_{2} / \mathrm{F}_{\mathrm{i}} \mathrm{O}_{2}$ ratio (P/F), as follows: mild, $\mathrm{P} / \mathrm{F}$ of 201 to $300 \mathrm{mmHg}$; moderate, $\mathrm{P} / \mathrm{F}$ of 101 to $200 \mathrm{mmHg}$; and severe, $\mathrm{P} / \mathrm{F}$ of $<100 \mathrm{mmHg}$.

Based on this knowledge, we conducted a prospective observational study to test the hypothesis that statin therapy improves the clinical course of sepsis-associated ARDS depending on disease severity (mild, moderate, or severe).

\section{Methods}

\section{Patients}

This study was approved by the University of Goettingen ethics committee in Goettingen, Germany (1/15/12) and conformed to the ethical principles of the Declaration of Helsinki. Written informed consent was obtained from all patients or their legal representatives. Adult Caucasian patients admitted to the surgical intensive care units (ICUs) of the University Medical Center of Goettingen between April 2012 and September 2014 were evaluated daily according to the American College of Chest Physicians/Society of Critical Care Medicine (ACCP/SCCM) criteria for sepsis $[15,16]$. Patients with sepsis were screened daily according to the Berlin definition of ARDS to identify those with sepsis-associated ARDS [14-16]. The patient exclusion criteria were as follows: those who i) were younger than 18 years of age; ii) were pregnant or nursing an infant; iii) were receiving immunosuppressive therapy; iv) had a documented myocardial infarction within the previous 6 weeks; v) had New York Heart Association functional class IV chronic heart failure; vi) were infected with human immunodeficiency virus; vii) had a do not resuscitate or do not treat order; viii) were not expected to survive the next 28 days because of an uncorrectable medical condition (e.g., poorly controlled neoplasm); ix) were in a chronic vegetative state with pronounced neurological impairment; $x$ ) were currently participating in any clinical trial (of a drug or device); xi) could not be fully evaluated during the study period; and xii) were a study-site employee or the family member of a study-site employee. Because interracial genetic differences may affect the clinical courses of infectious diseases, we exclusively recruited Caucasians for this observational study. Caucasians also comprise the greatest proportion of patients admitted to our surgical ICUs. According to pharmacogenetic studies, the frequency of polymorphisms in statin transporter genes vary markedly between populations and can have profound effects on statin pharmacokinetics [17, 18]. In particular, a common genetic variant of organic aniontransporting polypeptide $1 \mathrm{~B} 1$ with a diverse distribution among populations reduces the hepatic uptake of many statins, increasing the risks of statin-induced myopathy and adverse events [18, 19].

In our tertiary medical center (a member of the German ARDS network), the treatment goals for ARDS patients consist of supportive care and a protective strategy of lung ventilation using low tidal volumes to limit endinspiratory plateau pressure. A tidal volume of $6 \mathrm{cc} / \mathrm{kg}$ predicted body weight or lower is used to maintain an inspiratory plateau pressure of $<30 \mathrm{~cm}$ of water [20]. Patients with more severe hypoxemia exhibit a high positive end-expiratory pressure [21]. Patients with refractory hypoxemia are placed in the prone position to improve oxygenation [22, 23]. Additionally, rescue oxygenation is performed at our center using standardized extracorporeal membrane oxygenation (ECMO) therapy for patients with profound refractory hypoxemia [24]. ARDS patients also receive conservative intravenous fluid management to reduce pulmonary microvascular pressure and the likelihood of developing pulmonary edema [25]. 


\section{Data collection}

Death within 28 days of sepsis onset was recorded as the primary outcome variable. Two morbidity scores, the Sequential Organ Failure Assessment (SOFA) [26] and Acute Physiology and Chronic Health Evaluation (APACHE) II [27] scores, were evaluated at sepsis onset. Organ function was reassessed using SOFA scores over 28 days in the ICU to monitor morbidity. Organ support-free days (mechanical ventilation, vasopressor therapy, renal replacement therapy, and ECMO therapy) and the length of ICU stay were recorded as secondary outcome variables. The baseline that was used for support-free days was the length of ICU stay for each patient. Clinical data were collected from the electronic patient record system (IntelliSpace Critical Care and Anesthesia (ICCA); Philips Healthcare, Andover, Massachusetts, USA). All medical records, including microbiological findings and medication histories, were obtained from these electronic health records. Prior statin therapy and comorbidities were identified by examining physicians' notes, through anamnestic questionnaires of the patients or their legal representatives, and by consulting each patient's family doctor.

\section{Statistical analyses}

Statistical analyses were performed using Statistica software (version 10; StatSoft, Tulsa, Oklahoma, USA). The significance of the categorical variables was calculated using two-sided Fisher's exact or $\chi^{2}$ tests, as appropriate. Two continuous variables were compared using the Mann-Whitney test. Time-to-event data were compared using the log-rank test with Statistica package for Kaplan-Meier survival analysis. A power calculation was conducted using Statistica package for power analysis. To exclude the effects of potential confounders (age, gender and body mass index (BMI)) and covariates that varied at baseline (e.g., comorbidities and recent surgical history) on survival, we performed multivariate Cox regression analysis to examine survival time. A $P$ value of $<0.05$ was considered statistically significant. Propensity score matching was performed using the statistical computing software $\mathrm{R}$ (version 3.1.1) with MatchIt package (version 2.4-21).

\section{Results}

\section{Patients and baseline characteristics}

A total of 404 patients with sepsis developed ARDS and were enrolled in this study (Fig. 1). The distribution of the ARDS subgroups was $13 \%, 59 \%$, and $28 \%$ for mild, moderate, and severe ARDS, respectively. Among all of the patients, $27 \%$ were pretreated with statins, and statin therapy was continued over the observation period in this patient group. Most of the patients in the statin group were pretreated with simvastatin $(87.1 \%$, Table 1$)$, which was given at the same dose after admission. The patients who were pretreated with one of the other statins were switched to simvastatin (the standard statin in our ICUs) at an equivalent dose. Patients who were fed via a tube were still given statins. The patients underwent statin therapy because of associated comorbid conditions. The rate of statin therapy did not differ significantly among the three ARDS subgroups. Simvastatin (20 or $40 \mathrm{mg}$ ) was the most frequently used statin (87.1\%; Table 1$)$. The ages of the patients ranged from 19 to 92 years (median, 63 years; Table 1). The ARDS patients on statin therapy were significantly older than those who were not on this therapy (70 \pm 11 and $60 \pm 16$, respectively; $P<0.001$; Table 1$)$. No differences were recorded in gender or BMI between the two groups (Table 1). The proportion of patients with septic shock was significantly higher among the patients without statin therapy compared with those receiving this therapy (68\% and $52 \%$, respectively; $P=0.0035$ ). At baseline, the patients without statin therapy had significantly higher SOFA scores compared with those receiving therapy $(9.9 \pm 3.8$ and $8.9 \pm 3.4$, respectively; $P=0.0158)$. No differences were found in APACHE II scores with respect to statin therapy at baseline (Table 1).

Regarding comorbidities at baseline, the frequencies of several preexisting diseases were significantly higher in the patients on statin therapy (i.e., arterial hypertension, history of myocardial infarction, renal dysfunction, noninsulindependent diabetes mellitus, insulin-dependent diabetes mellitus, and history of stroke; Table 1). Furthermore, the number of patients with a recent surgical history also significantly differed between the two groups and there was no difference in the site of infection between the groups (Table 1). The patients on statin therapy required significantly less vasopressor therapy compared with those who were not on this therapy (52\% and $68 \%$, respectively; $P=0.0035$; Table 1 ). We were able to follow all of these patients for a maximum of 90 days after sepsis onset.

\section{Outcomes \\ Mortality}

An analysis of the 28-day mortality risk of the patients according to ARDS severity revealed a significantly higher mortality rate among the patients with severe ARDS compared with those with mild or moderate ARDS $(P<0.0001$, log-rank test; Fig. 2).

Furthermore, to detect the impact of statin therapy on the outcome of sepsis-associated ARDS and its dependency on disease severity (mild, moderate, or severe), Kaplan-Meier survival analysis (mean outcome parameter) was performed to assess 28-day survival for these three groups of patients (Fig. 3). Treatment with statins significantly impacted the 28-day survival exclusively among the patients with severe sepsis-associated ARDS. Those with severe ARDS who were on statin therapy 


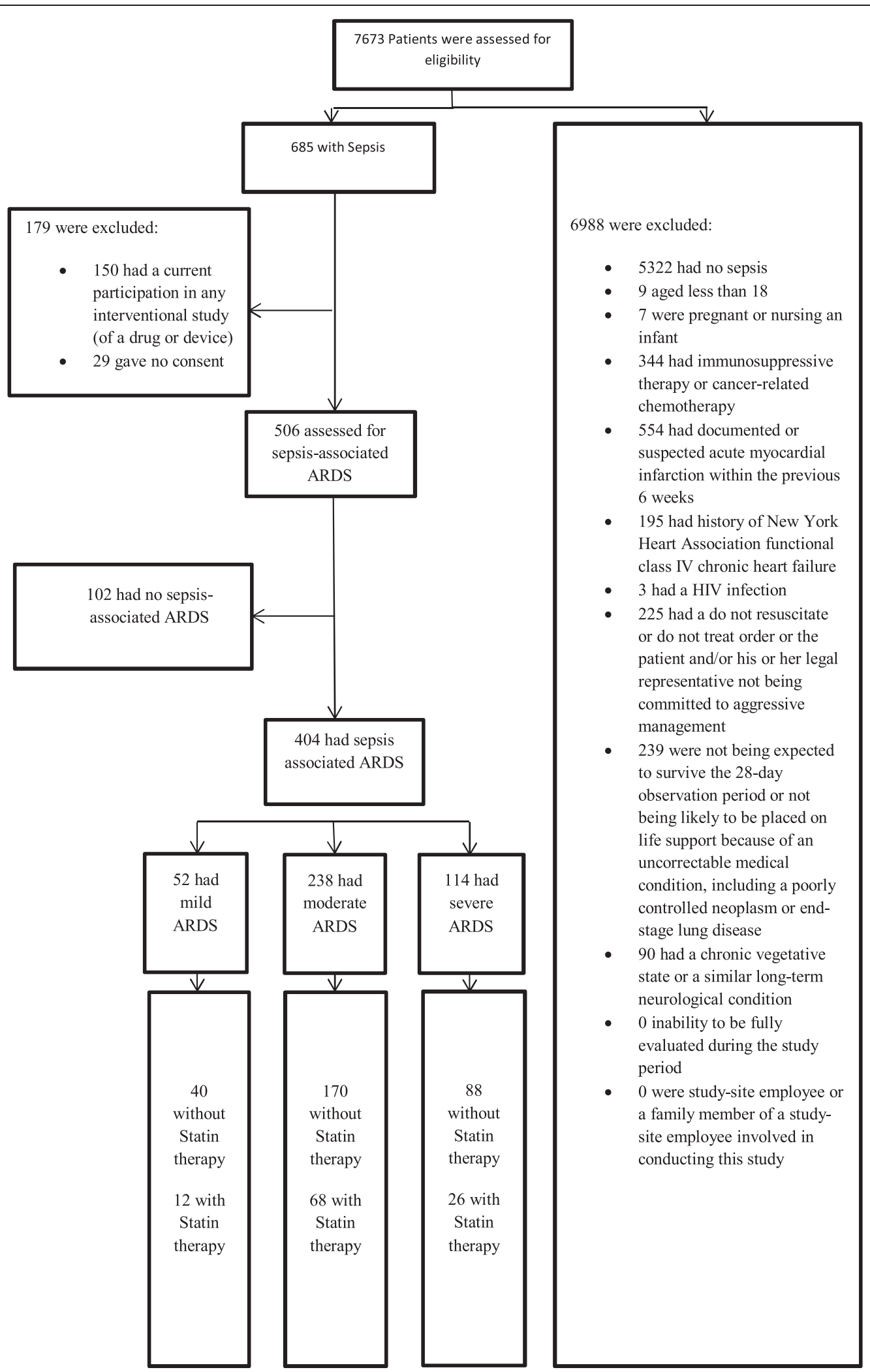

Fig. 1 Population of patients who were screened and followed-up 
Table 1 Patients' baseline characteristics according to statin usage

\begin{tabular}{|c|c|c|c|c|}
\hline & $\begin{array}{l}\text { All } \\
(n=404)\end{array}$ & $\begin{array}{l}\text { ARDS } \\
\text { without statins } \\
(\mathrm{n}=296)\end{array}$ & $\begin{array}{l}\text { with statins } \\
(n=108)\end{array}$ & $P$ value \\
\hline Age, years & $63 \pm 15$ & $60 \pm 16$ & $70 \pm 11$ & $<0.0001$ \\
\hline Male, \% & 68 & 65 & 76 & 0.0533 \\
\hline Body mass index & $28 \pm 7$ & $28 \pm 8$ & $28 \pm 5$ & 0.4304 \\
\hline \multicolumn{5}{|l|}{ Severity of sepsis } \\
\hline Sepsis/severe sepsis, \% & 36 & 32 & 48 & 0.0035 \\
\hline Septic shock, \% & 64 & 68 & 52 & 0.0035 \\
\hline Sequential Organ Failure Assessment score & $9.6 \pm 3.7$ & $9.9 \pm 3.8$ & $8.9 \pm 3.4$ & 0.0158 \\
\hline Acute Physiology and Chronic Health Evaluation (APACHE II) score & $22.1 \pm 6.8$ & $22.1 \pm 7.0$ & $22.1 \pm 6.0$ & 0.9888 \\
\hline \multicolumn{5}{|l|}{ Comorbidities, \% } \\
\hline Hypertension & 56 & 48 & 78 & $<0.0001$ \\
\hline History of myocardial infarction & 6 & 2 & 19 & $<0.0001$ \\
\hline Chronic obstructive pulmonary disease & 18 & 18 & 20 & 0.5615 \\
\hline Renal dysfunction & 11 & 9 & 18 & 0.0192 \\
\hline Noninsulin-dependent diabetes mellitus & 9 & 7 & 15 & 0.0332 \\
\hline Insulin-dependent diabetes mellitus & 11 & 9 & 19 & 0.0069 \\
\hline Chronic liver disease & 7 & 7 & 7 & 1.0000 \\
\hline History of cancer & 20 & 21 & 19 & 0.8891 \\
\hline History of stroke & 5 & 4 & 11 & 0.0073 \\
\hline \multicolumn{5}{|l|}{ Recent surgical history, \% } \\
\hline Elective surgery & 26 & 21 & 39 & 0.0005 \\
\hline Emergency surgery & 54 & 56 & 49 & 0.2168 \\
\hline No history of surgery & 20 & 23 & 12 & 0.0169 \\
\hline Site of infection, \% & & & & 0.1339 \\
\hline Lung & 60 & 57 & 70 & \\
\hline Abdomen & 23 & 25 & 17 & \\
\hline Bone or soft tissue & 5 & 5 & 2 & \\
\hline Surgical wound & 2 & 2 & 1 & \\
\hline Urogenital & 2 & 2 & 2 & \\
\hline Primary bacteremia & 6 & 5 & 7 & \\
\hline Other & 4 & 4 & 1 & \\
\hline \multicolumn{5}{|l|}{ Organ support, \% } \\
\hline Mechanical ventilation & 90 & 91 & 86 & 0.1393 \\
\hline Use of vasopressor & 64 & 68 & 52 & 0.0035 \\
\hline Renal replacement therapy & 10 & 9 & 11 & 0.5697 \\
\hline \multicolumn{5}{|l|}{ Statin drugs, \% } \\
\hline Simvastatin & 23 & & 87 & \\
\hline Pravastatin & 2 & & 6 & \\
\hline Atorvastatin & 1 & & 6 & \\
\hline Fluvastatin & 0 & & 1 & \\
\hline
\end{tabular}

The data are presented as the mean \pm SD or as a percentage 


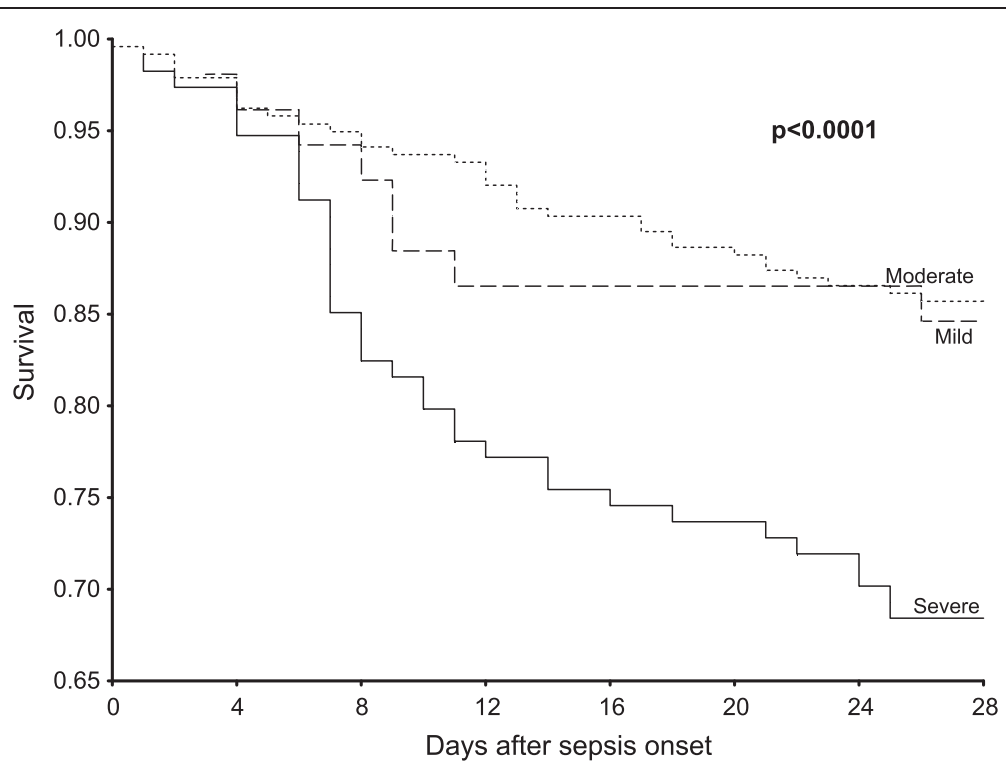

Fig. 2 Kaplan-Meier survival analysis of 28-day survival according to acute respiratory distress syndrome (ARDS) severity. The Kaplan-Meier survival curves censored at day 28 for each ARDS group (mild, moderate, and severe). The mortality risk among the patients under study was higher for those with severe ARDS compared with those with mild and moderate ARDS $(P<0.0001$, log-rank test)
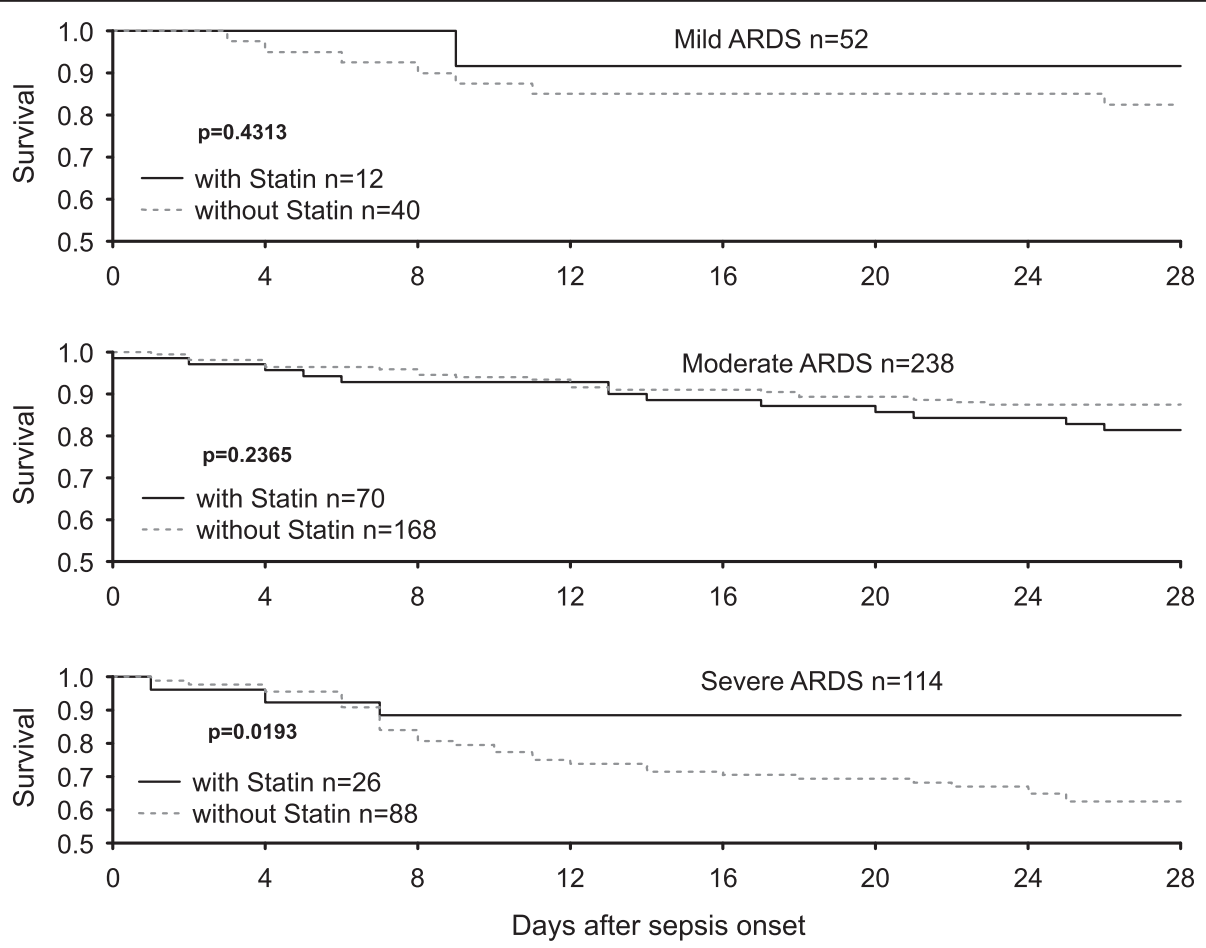

Fig. 3 Kaplan-Meier survival analysis of 28-day survival according to statin therapy for the three acute respiratory distress syndrome (ARDS) groups. The Kaplan-Meier survival curves censored at day 28 for each ARDS group (mild, moderate, and severe) according to the presence of statin therapy. Treatment with statins only significantly impacted 28-day survival among the patients with severe sepsis-associated ARDS $(P=0.0193$, log-rank test) 
had a lower 28-day mortality rate compared with those who were not on this therapy $(11.5 \%$ and $37.5 \%$, respectively; $P=0.0193$; Fig. 3 ). After performing propensity score matching, survival analysis remained significant with a marginal change $(P=0.0205$ (after propensity score matching) vs. $P=0.0193$ (without propensity score matching); Fig. 4). There were no differences in the 28-day mortality risk between the patients with statin therapy and those without therapy in the mild and moderate sepsis-associated ARDS groups (Fig. 3).

\section{Multivariate analysis}

To exclude the effects of several confounders and baseline variables on 28-day survival among the patients with severe ARDS and to determine whether statin therapy is an independent prognostic factor for 28-day survival, the baseline patient characteristics in the severe ARDS group were analyzed according to the presence of statin therapy (Table 2). Subsequently, we performed multivariate Cox regression analysis and included statin therapy, potential confounders (age, gender, BMI, SOFA and APACHE II scores, and Corticosteroid therapy (given to patients for septic shock)) and covariates that varied at baseline (septic shock, arterial hypertension, and histories of stroke and elective surgery; Table 2). Multivariate Cox regression analysis revealed that the absence of statin therapy was an independent prognostic indicator of 28-day mortality risk (hazard ratio, 5.46; $95 \%$ CI, 1.38-21.70; $P=0.0156$ ) (Table 3).

\section{Disease severity}

Analysis of SOFA scores obtained during the ICU stays of the patients with severe ARDS revealed significantly higher scores among those without statin therapy for three organ-specific SOFA scores (the cardiovascular, central nervous system, and hepatic scores; Table 4). Furthermore, the patients with severe ARDS who received statin therapy had significantly more vasopressor-free days compared with those without this therapy $(13 \pm 7$ and $9 \pm 7$, respectively; $P=0.0034$ ). The severe ARDS patients on statin therapy required less ECMO therapy and had more ECMO-free days compared with those without statin therapy (18 \pm 9 and $15 \pm 9$, respectively; $P=0.0873$; Table 4 ). Distribution of infection types is shown in Table 5 . Additional results regarding disease severity, microbiological findings and anti-infective agents were added to Additional file 1: Tables S1-S4.

\section{Inflammatory parameters}

The patients with statin therapy in the severe ARDS group had reduced C-reactive protein (CRP) levels compared with those without this therapy $(125 \pm 79$ and $166 \pm 85$, respectively; $P=0.1400$ ). Furthermore, the severe ARDS patients with statin therapy had lower levels of procalcitonin compared with those without therapy $(3.2 \pm 9.5$ and $7.3 \pm 15.1$, respectively; $P=$ 0.0743; Table 4).

\section{Discussion}

This prospective observational study addresses the question of whether statin therapy in patients with sepsis-associated ARDS is associated with 28-day survival, according to the

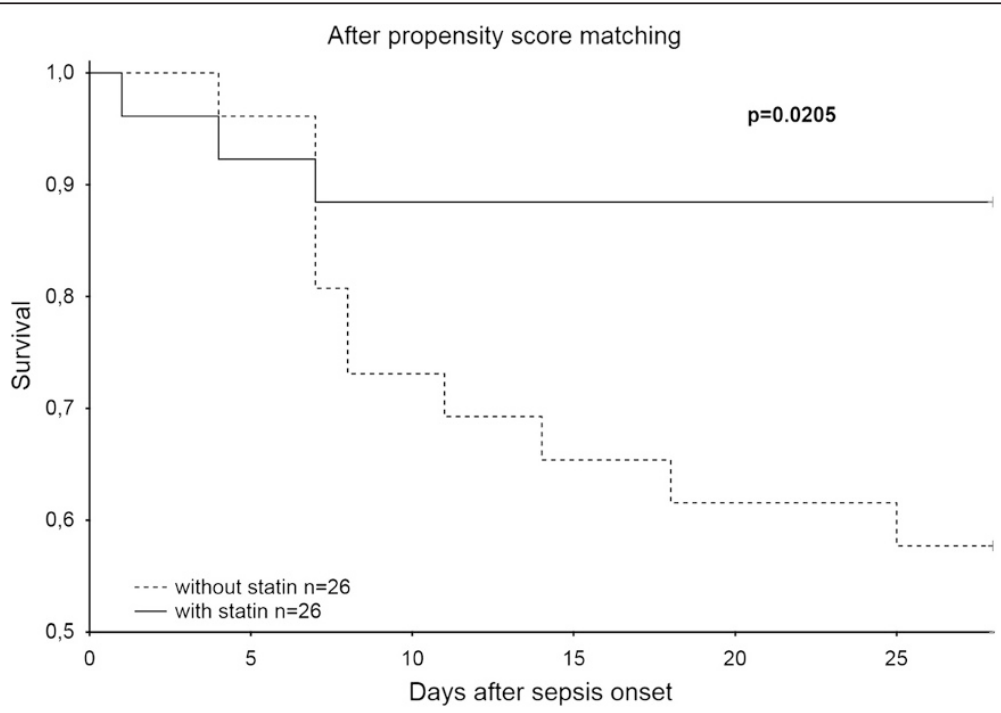

Fig. 4 Kaplan-Meier survival analysis of 28-day survival after propensity score matching in the severe acute respiratory distress syndrome (ARDS) groups. The Kaplan-Meier survival curves censored at day 28 for severe ARDS group according to the presence of statin therapy. Treatment with statins significantly impacted 28-day survival among the patients with severe sepsis-associated ARDS $(P=0.0205$, log-rank test) 
Table 2 Severe acute respiratory distress syndrome (ARDS) patients' baseline characteristics with regard to statin usage

\begin{tabular}{|c|c|c|c|c|}
\hline & $\begin{array}{l}\text { All } \\
(n=114)\end{array}$ & $\begin{array}{l}\text { Severe ARDS } \\
\text { without statins } \\
(\mathrm{n}=88)\end{array}$ & $\begin{array}{l}\text { with statins } \\
(\mathrm{n}=26)\end{array}$ & $P$ value \\
\hline Age, years & $61 \pm 14$ & $59 \pm 15$ & $67 \pm 10$ & 0.0159 \\
\hline Male, \% & 66 & 64 & 73 & 0.4822 \\
\hline Body mass index & $30 \pm 8$ & $30 \pm 9$ & $30 \pm 6$ & 0.5590 \\
\hline \multicolumn{5}{|l|}{ Severity of sepsis } \\
\hline Sepsis/severe sepsis, \% & 24 & 19 & 39 & 0.0644 \\
\hline Septic shock, \% & 76 & 81 & 62 & 0.0644 \\
\hline Sequential Organ Failure Assessment score & $11.0 \pm 3.5$ & $11.2 \pm 3.5$ & $10.6 \pm 3.4$ & 0.2511 \\
\hline Acute Physiology and Chronic Health Evaluation (APACHE II) score & $23.7 \pm 6.7$ & $23.4 \pm 6.9$ & $24.5 \pm 5.7$ & 0.3250 \\
\hline \multicolumn{5}{|l|}{ Comorbidities, \% } \\
\hline Hypertension & 58 & 51 & 81 & 0.0073 \\
\hline History of myocardial infarction & 4 & 2 & 12 & 0.0772 \\
\hline Chronic obstructive pulmonary disease & 18 & 19 & 15 & 0.7787 \\
\hline Renal dysfunction & 10 & 9 & 12 & 0.7114 \\
\hline Noninsulin-dependent diabetes mellitus & 9 & 7 & 15 & 0.2323 \\
\hline Insulin-dependent diabetes mellitus & 12 & 13 & 12 & 1.0000 \\
\hline Chronic liver disease & 4 & 2 & 12 & 0.0772 \\
\hline History of cancer & 19 & 22 & 12 & 0.3964 \\
\hline History of stroke & 6 & 2 & 19 & 0.0066 \\
\hline \multicolumn{5}{|l|}{ Recent surgical history, \% } \\
\hline Elective surgery & 25 & 19 & 42 & 0.0217 \\
\hline Emergency surgery & 46 & 49 & 35 & 0.2635 \\
\hline No history of surgery & 30 & 32 & 23 & 0.4704 \\
\hline Site of infection, \% & & & & 0.5675 \\
\hline Lung & 71 & 68 & 81 & \\
\hline Abdomen & 11 & 13 & 4 & \\
\hline Bone or soft tissue & 7 & 8 & 4 & \\
\hline Surgical wound & 1 & 1 & 0 & \\
\hline Urogenital & 1 & 1 & 0 & \\
\hline Primary bacteremia & 7 & 6 & 12 & \\
\hline Other & 3 & 3 & 0 & \\
\hline \multicolumn{5}{|l|}{ Organ support, \% } \\
\hline Mechanical ventilation & 96 & 96 & 96 & 1.0000 \\
\hline Use of vasopressor & 76 & 81 & 62 & 0.0644 \\
\hline Renal replacement therapy & 11 & 10 & 12 & 1.0000 \\
\hline \multicolumn{5}{|l|}{ Statin drugs, \% } \\
\hline Simvastatin & 20 & & 96 & \\
\hline Pravastatin & 1 & & 4 & \\
\hline
\end{tabular}

The data are presented as the mean \pm SD or as a percentage

new Berlin definition of ARDS severity (mild, moderate, and severe). The main finding of this investigation was that patients with severe sepsis-associated ARDS who received statin therapy had a significantly better 28-day survival rate compared with those without this therapy.

The observed beneficial effect of statin therapy on 28day survival, which was nearly exclusively observed in 
Table 3 Cox regression analysis of severe acute respiratory distress syndrome patients

\begin{tabular}{llll}
\hline Variable & Hazard ratio & $95 \% \mathrm{Cl}$ & $P$ value \\
\hline Age & 1.00 & $0.98-1.04$ & 0.5190 \\
Male gender & 1.13 & $0.55-2.34$ & 0.7331 \\
Body mass index & 0.99 & $0.95-1.04$ & 0.7431 \\
$\begin{array}{l}\text { Sequential Organ } \\
\text { Failure Assessment }\end{array}$ & 0.97 & $0.82-1.15$ & 0.7618 \\
Acute Physiology and & 1.06 & $0.98-1.14$ & 0.1287 \\
$\begin{array}{l}\text { Chronic Health Evaluation } \\
\text { (APACHE II) }\end{array}$ & & & \\
Septic shock & 0.74 & $0.24-2.33$ & 0.6049 \\
Arterial hypertension & 1.38 & $0.66-2.91$ & 0.3935 \\
History of stroke & 0.60 & $0.12-3.04$ & 0.5358 \\
Elective surgery & 0.69 & $0.31-1.53$ & 0.3556 \\
Corticosteroid therapy & 1.16 & $0.54-2.50$ & 0.6983 \\
No statin therapy & 5.47 & $1.38-21.70$ & 0.0156 \\
\hline
\end{tabular}

the patients with severe sepsis-associated ARDS, is in accordance with recent studies showing that the various ARDS subgroups (mild, moderate, and severe) are associated with distinct histopathological features that may impact the therapeutic potentials of or responses to ARDS-specific treatments [28]. According to Thille et al. [28], patients with severe ARDS comprise a homogeneous group characterized by a high proportion of diffuse alveolar damage compared with those with mild or moderate ARDS. Diffuse alveolar damage is accompanied by a severe inflammatory state; therefore, patients with severe ARDS are more likely to benefit from the anti-inflammatory, pleiotropic effects of statin therapy. Our results confirm previous reports of the beneficial effects of statin therapy continuation on the survival of patients with sepsis $[29,30]$. In a recent multicenter prospective study that included patients with severe sepsis, Kruger et al. [29] showed that the continuation of atorvastatin in patients with severe sepsis who have received statin pretreatment is associated with improved survival.

Our findings of better survival among the patients with severe ARDS who received continuous statin therapy are of particular importance because there is currently no specific effective treatment that improves the clinical course of patients with severe ARDS. Current treatment modalities focus on symptomatic treatments, including mechanical ventilation and organ support. This evidence of a beneficial impact of statin continuation on severe ARDS patients suggests that statin therapy should be continued for all critically ill patients who are at high risk of developing sepsis or infection, i.e., those undergoing surgical procedures with a high infection risk. Furthermore, according to our investigation, preventive statin treatment in patients with a high predisposition to sepsis or sepsis-associated ARDS may be of potential therapeutic significance and should be addressed in future studies. Analogous to evidence demonstrated by previous cardiovascular studies that a statin treatment duration of 8 to 12 weeks is needed to achieve pleotropic effects [31-33], we believe that patients with sepsis-associated ARDS must be pretreated with statins for 8 to 12 weeks to achieve beneficial effects in this patient group.

Moreover, we found that the beneficial impact of statin therapy was accompanied by significantly lower organspecific SOFA scores in three organ systems (the cardiovascular, central nervous, and hepatic systems) among the patients on statin therapy (Table 4). The observed lower cardiovascular scores might have been due to anti-inflammatory effects of the statin therapy, which inhibited the release of inflammatory mediators and resulted in less vasodilatation in the patients in this group [5]. In accordance with the lower cardiovascular SOFA scores, severe sepsis-associated ARDS patients also had significantly more vasopressor-free days compared with those who were not on statin therapy (Table 4). Similarly, the observed lower hepatic SOFA scores can be explained by the fact that statin therapy has a beneficial effect on liver function [5]. As shown by Arnaud et al. [34], statins exert direct anti-inflammatory effects on hepatocytes by reducing IL-6-induced CRP production.

Although they did not reach statistical significance, the lower inflammatory, CRP, and procalcitonin levels among the patients on continuous statin therapy (Table 4) are in accordance with previous observations showing an effect of statin therapy on reducing inflammatory parameters in patients with severe sepsis $[8,29]$ and in a human model of acute lung injury [6].

There are some limitations to this study. This is an observational study; therefore, it did not apply the ideal methodology for assessing the effects of a drug. A future randomized controlled (RCT) study would be much more suitable, although this study does provide impetus for potential studies to examine the use of statins in severe ARDS. This type of RCT would be very difficult to conduct because the duration of statin pretreatment and the dose required to achieve beneficial effects on the clinical course for patients with severe sepsis-associated ARDS are unknown. A further potential limitation is that plasma statin levels were not measured. Therefore, we cannot rule out the fact that statin levels were not within the therapeutic range. However, according to previous investigations, high plasma levels of statins are achieved (especially in critically ill patients in the ICU) even after the administration of a single dose $[8,35]$. Moreover, the plasma level of statins required to induce anti-inflammatory effects is not known. Furthermore, because no previous investigations have addressed the effects of statin therapy on ARDS according to disease 
Table 4 Disease severity among patients with severe acute respiratory distress syndrome (ARDS) according to statin therapy

\begin{tabular}{|c|c|c|c|c|}
\hline & $\begin{array}{l}\text { All } \\
(n=114)\end{array}$ & $\begin{array}{l}\text { Severe ARDS } \\
\text { without statins } \\
(\mathrm{n}=88)\end{array}$ & $\begin{array}{l}\text { with statins } \\
(n=26)\end{array}$ & $P$ value \\
\hline Sequential Organ Failure Assessment (SOFA) & $9.0 \pm 3.7$ & $9.3 \pm 3.9$ & $7.7 \pm 2.6$ & 0.1051 \\
\hline SOFA-Respiratory score & $2.6 \pm 0.6$ & $2.6 \pm 0.6$ & $2.6 \pm 0.6$ & 0.9677 \\
\hline SOFA-Cardiovascular score & $2.0 \pm 1.1$ & $2.1 \pm 1.1$ & $1.5 \pm 1.0$ & 0.0063 \\
\hline SOFA-Central nervous System score & $2.4 \pm 1.0$ & $2.5 \pm 1.0$ & $2.0 \pm 1.0$ & 0.0203 \\
\hline SOFA-Renal score & $1.0 \pm 1.2$ & $0.9 \pm 1.2$ & $1.1 \pm 1.0$ & 0.2110 \\
\hline SOFA-Coagulation score & $0.5 \pm 0.7$ & $0.6 \pm 0.8$ & $0.3 \pm 0.4$ & 0.2734 \\
\hline SOFA-Hepatic score & $0.5 \pm 0.7$ & $0.5 \pm 0.8$ & $0.3 \pm 0.5$ & 0.0218 \\
\hline \multicolumn{5}{|l|}{ Mortality analysis, \% } \\
\hline Death at day 28 & 32 & 38 & 12 & 0.0153 \\
\hline Death at day 90 & 42 & 47 & 27 & 0.1126 \\
\hline Length of stay in ICU, days & $20 \pm 15$ & $19 \pm 15$ & $22 \pm 16$ & 0.4290 \\
\hline \multicolumn{5}{|l|}{ Organ support-free days } \\
\hline Vasopressor-free days & $10 \pm 7$ & $9 \pm 7$ & $13 \pm 7$ & 0.0034 \\
\hline Ventilator-free days & $3 \pm 3$ & $2 \pm 3$ & $3 \pm 3$ & 0.1824 \\
\hline Dialysis-free days & $15 \pm 8$ & $14 \pm 8$ & $17 \pm 8$ & 0.2532 \\
\hline Extracorporeal membrane oxygenation-free days & $15 \pm 9$ & $15 \pm 9$ & $18 \pm 9$ & 0.0873 \\
\hline \multicolumn{5}{|l|}{ Inflammatory values } \\
\hline 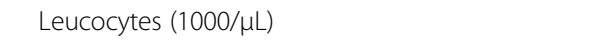 & $13 \pm 5$ & $13 \pm 5$ & $12 \pm 4$ & 0.5168 \\
\hline C-reactive protein (mg/L) (n) & $155 \pm 84(46)$ & $166 \pm 85(33)$ & $125 \pm 79(13)$ & 0.1400 \\
\hline Procalcitonin (ng/dL) (n) & $6.4 \pm 14.0(109)$ & $7.3 \pm 15.1(85)$ & $3.2 \pm 9.5(24)$ & 0.0743 \\
\hline \multicolumn{5}{|l|}{ Kidney values } \\
\hline Urine output (mL/day) & $2977 \pm 1442$ & $2911 \pm 1440$ & $3201 \pm 1457$ & 0.5659 \\
\hline Urine output (mL/kg/h) & $1.5 \pm 0.8$ & $1.4 \pm 0.7$ & $1.5 \pm 0.8$ & 0.7356 \\
\hline Creatinine (mg/dL) & $1.4 \pm 0.9$ & $1.3 \pm 1.0$ & $1.6 \pm 0.8$ & 0.0363 \\
\hline \multicolumn{5}{|l|}{ Liver values } \\
\hline AST (IU/L) (n) & $391 \pm 1248(81)$ & $472 \pm 1395$ & $85 \pm 80(17)$ & 0.0611 \\
\hline $\mathrm{ALT}(\mathrm{IU} / \mathrm{L})(\mathrm{n})$ & $135 \pm 288(113)$ & $157 \pm 324(87)$ & $63 \pm 57(26)$ & 0.1257 \\
\hline Bilirubin (mg/dL) & $1.5 \pm 2.7$ & $1.7 \pm 3.0$ & $0.8 \pm 0.7$ & 0.0511 \\
\hline
\end{tabular}

The data are presented as the mean \pm SD or as a percentage

severity, we were unable to conduct power calculations at the beginning of the study to estimate a sample size with sufficient power. However, ad hoc power analysis yielded a power of 0.87 , according to our observation of $11.5 \%$ mortality in the severe ARDS patients on statin

Table 5 Infection types during the observational period

\begin{tabular}{llll}
\hline Infection type & \multicolumn{2}{l}{$\begin{array}{l}\text { Severe acute respiratory distress syndrome } \\
\text { without statins } \\
(\mathrm{n}=88)\end{array}$} & $\begin{array}{l}\text { with statins } \\
(\mathrm{n}=26)\end{array}$ \\
\hline Gram-negative & $71 \%$ & $65 \%$ & \\
Gram-positive & $78 \%$ & $96 \%$ & 0.6347 \\
Fungal & $61 \%$ & $81 \%$ & 0.0407 \\
Viral & $10 \%$ & $15 \%$ & 0.0985 \\
\hline
\end{tabular}

therapy compared with $37.5 \%$ mortality in those who were not on this therapy. Therefore, our investigated cohort of 404 patients with sepsis-associated ARDS was sufficient to address our hypotheses.

To the best of our knowledge, this investigation is the first to evaluate the impact of statin therapy on the survival of patients with sepsis-associated ARDS according to the new Berlin definition of ARDS. Our results provide evidence that confirms the valuable and important application of the new Berlin definition in guiding the therapy of critically ill ARDS patients and underscores the potential therapeutic benefits of statins in this highrisk patient cohort. Further study is warranted to elucidate the potential beneficial effects of statin therapy in patients with severe ARDS. 


\section{Conclusions}

This prospective observational cohort study has confirmed the hypothesis that statin therapy does improve the clinical course of sepsis-associated ARDS depending on disease severity (mild, moderate, or severe). Therefore, the use of continuous statin therapy in sepsis patients with a prior history of receiving this therapy who develop severe ARDS has an independent beneficial impact on 28-day survival. Further study is warranted to explain this potential effect.

\section{Additional file}

Additional file 1: The additional file 1 includes information about vital parameters, laboratory parameters, kidney parameters and inflammation values, recorded microbiological findings and anti-infective agents.

\section{Abbreviations}

APACHE: Acute physiology and chronic health evaluation; ARDS: Acute respiratory distress syndrome; BMl: Body mass index; CRP: C-reactive protein; ECMO: Extracorporeal membrane oxygenation; ICU: Intensive care unit; SOFA: Sequential organ failure assessment.

\section{Competing interests}

The authors declare that they have no competing interests.

\section{Authors' contributions}

All authors contributed to the study design, data acquisition or analysis, and data interpretation. Specifically, MS, AP, MG, and MB participated in the study design and supervised patient enrollment and clinical data monitoring. TB contributed to the study design and conception and performed and approved the statistical analyses. AM and $\mathrm{JH}$ designed the study, supervised the sample and data collection, performed analyses, and drafted the manuscript. All authors were involved in either the manuscript drafting or revision. All authors have approved the final version of the manuscript.

\section{Acknowledgments}

The authors thank the staff of the ICUs of the Department of Anesthesiology and the Department of General and Visceral Surgery, all of whom were involved in patient care and monitoring. The authors also thank Benjamin Liese, Simon Wilmers, Yvonne Klee, Sebastian Gerber, Chang Ho Hong, and Evelyn Mulwande for their help with data acquisition. This study was supported by the German Research Foundation (DFG) and the Open Access Publication Funds of Göttingen University.

\section{Author details}

${ }^{1}$ Department of Anesthesiology, University Medical Center, Georg August University, D-37075 Goettingen, Germany. '2Department of Cardiothoracic Transplantation \& Mechanical Support, Royal Brompton and Harefield Hospital, Harefield, Hill End Road, UB9 6JH London, UK. ${ }^{3}$ Department of General and Visceral Surgery, University Medical Center, Georg August University, D-37075 Goettingen, Germany. ${ }^{4}$ Department of Medical Statistics, University Medical Center, Georg August University, D-37075 Goettingen, Germany.

Received: 4 February 2015 Accepted: 14 May 2015

Published online: 01 June 2015

\section{References}

1. Rubenfeld GD, Caldwell E, Peabody E, Weaver J, Martin DP, Neff M, et al. Incidence and outcomes of acute lung injury. N Engl J Med. 2005;353:1685-93.

2. Bernard GR, Artigas A, Brigham KL, Carlet J, Falke K, Hudson L, et al. The American-European Consensus Conference on ARDS. Definitions, mechanisms, relevant outcomes, and clinical trial coordination. Am J Respir Crit Care Med. 1994;149:818-24
3. Raghavendran K, Pryhuber GS, Chess PR, Davidson BA, Knight PR, Notter RH. Pharmacotherapy of acute lung injury and acute respiratory distress syndrome. Curr Med Chem. 2008;15:1911-24.

4. Jacobson JR, Barnard JW, Grigoryev DN, Ma SF, Tuder RM, Garcia JG Simvastatin attenuates vascular leak and inflammation in murine inflammatory lung injury. Am J Physiol Lung Cell Mol Physiol. 2005;288:L1026-32.

5. Jain MK, Ridker PM. Anti-inflammatory effects of statins: clinical evidence and basic mechanisms. Nat Rev Drug Discov. 2005;4:977-87.

6. Shyamsundar M, McKeown ST, O'Kane CM, Craig TR, Brown V, Thickett DR, et al. Simvastatin decreases lipopolysaccharide-induced pulmonary inflammation in healthy volunteers. Am J Respir Crit Care Med. 2009;179:1107-14.

7. Almog Y, Shefer A, Novack V, Maimon N, Barski L, Eizinger M, et al. Prior statin therapy is associated with a decreased rate of severe sepsis. Circulation. 2004;110:880-5.

8. Craig TR, Duffy MJ, Shyamsundar M, McDowell C, O'Kane CM, Elborn JS, et al. A randomized clinical trial of hydroxymethylglutaryl- coenzyme a reductase inhibition for acute lung injury (The HARP Study). Am J Respir Crit Care Med. 2011;183:620-6.

9. Liappis AP, Kan VL, Rochester CG, Simon GL. The effect of statins on mortality in patients with bacteremia. Clin Infect Dis. 2001;33:1352-7.

10. Thomsen RW, Hundborg HH, Johnsen SP, Pedersen L, Sorensen HT, Schonheyder HC, et al. Statin use and mortality within 180 days after bacteremia: a population-based cohort study. Crit Care Med. 2006;34:1080-6.

11. Kor DJ, Iscimen R, Yilmaz M, Brown MJ, Brown DR, Gajic O. Statin administration did not influence the progression of lung injury or associated organ failures in a cohort of patients with acute lung injury. Intensive Care Med. 2009:35:1039-46.

12. McAuley DF, Laffey JG, O'Kane CM, Perkins GD, Mullan B, Trinder TJ, et al. Simvastatin in the acute respiratory distress syndrome. N Engl J Med. 2014;371:1695-703.

13. National Heart, Lung, and Blood Institute ARDS Clinical Trials Network Truwit JD, Bernard GR, Steingrub J, Matthay MA, Liu KD, et al. Rosuvastatin for sepsis-associated acute respiratory distress syndrome. N Engl J Med. 2014;370:2191-200

14. Ferguson ND, Fan E, Camporota L, Antonelli M, Anzueto A, Beale R, et al. The Berlin definition of ARDS: an expanded rationale, justification, and supplementary material. Intensive Care Med. 2012:38:1573-82.

15. Bone RC, Balk RA, Cerra FB, Dellinger RP, Fein AM, Knaus WA, et al. Definitions for sepsis and organ failure and guidelines for the use of innovative therapies in sepsis. The ACCP/SCCM Consensus Conference Committee. American College of Chest Physicians/Society of Critical Care Medicine. 1992. Chest. 2009;136, e28.

16. Levy MM, Fink MP, Marshall JC, Abraham E, Angus D, Cook D, et al. 2001 SCCM/ESICM/ACCP/ATS/SIS International Sepsis Definitions Conference. Crit Care Med. 2003;31:1250-6.

17. Niemi M. Transporter pharmacogenetics and statin toxicity. Clin Pharmacol Ther. 2010;87:130-3.

18. Pasanen MK, Neuvonen PJ, Niemi M. Global analysis of genetic variation in SLCO1B1. Pharmacogenomics. 2008;9:19-33.

19. Group SC, Link E, Parish S, Armitage J, Bowman L, Heath S, et al. SLCO1B1 variants and statin-induced myopathy-a genome-wide study. N Engl J Med. 2008:359:789-99.

20. Ventilation with lower tidal volumes as compared with traditional tidal volumes for acute lung injury and the acute respiratory distress syndrome. The Acute Respiratory Distress Syndrome Network. New Engl J Med. 2000;342:1301-08

21. Briel M, Meade M, Mercat A, Brower RG, Talmor D, Walter SD, et al. Higher vs lower positive end-expiratory pressure in patients with acute lung injury and acute respiratory distress syndrome: systematic review and meta-analysis. JAMA. 2010;303:865-73.

22. Abroug F, Ouanes-Besbes L, Dachraoui F, Ouanes I, Brochard L. An updated study-level meta-analysis of randomised controlled trials on proning in ARDS and acute lung injury. Crit Care (London, England). 2011;15:R6.

23. Sud S, Friedrich JO, Taccone P, Polli F, Adhikari NK, Latini R, et al. Prone ventilation reduces mortality in patients with acute respiratory failure and severe hypoxemia: systematic review and meta-analysis. Intensive Care Med. 2010;36:585-99

24. Peek GJ, Mugford M, Tiruvoipati R, Wilson A, Allen E, Thalanany MM, et al. Efficacy and economic assessment of conventional ventilatory support versus extracorporeal membrane oxygenation for severe adult respiratory 
failure (CESAR): a multicentre randomised controlled trial. Lancet. 2009:374:1351-63.

25. National Heart, Lung, and Blood Institute Acute Respiratory Distress Syndrome Clinical Trials Network, Wiedemann HP, Wheeler AP, Bernard GR, Thompson BT, Hayden D, et al. Comparison of two fluid-management strategies in acute lung injury. N Engl J Med. 2006;354:2564-75.

26. Vincent JL, de Mendonca A, Cantraine F, Moreno R, Takala J, Suter PM, et al. Use of the SOFA score to assess the incidence of organ dysfunction/failure in intensive care units: results of a multicenter, prospective study. Working group on 'sepsis-related problems' of the European Society of Intensive Care Medicine. Crit Care Med. 1998;26:1793-800.

27. Knaus WA, Draper EA, Wagner DP, Zimmerman JE. APACHE II: a severity of disease classification system. Crit Care Med. 1985;13:818-29.

28. Thille AW, Esteban A, Fernandez-Segoviano P, Rodriguez JM, Aramburu JA, Penuelas $\mathrm{O}$, et al. Comparison of the Berlin definition for acute respiratory distress syndrome with autopsy. Am J Respir Crit Care Med. 2013;187:761-7.

29. Kruger P, Bailey M, Bellomo R, Cooper DJ, Harward M, Higgins A, et al. A multicenter randomized trial of atorvastatin therapy in intensive care patients with severe sepsis. Am J Respir Crit Care Med. 2013;187:743-50.

30. Kruger P, Fitzsimmons K, Cook D, Jones M, Nimmo G. Statin therapy is associated with fewer deaths in patients with bacteraemia. Intensive Care Med. 2006:32:75-9.

31. Eichstadt HW, Eskotter H, Hoffman I, Amthauer HW, Weidinger G. Improvement of myocardial perfusion by short-term fluvastatin therapy in coronary artery disease. Am J Cardiol. 1995;76:122A-5.

32. O'Driscoll G, Green D, Taylor RR. Simvastatin, an HMG-coenzyme A reductase inhibitor, improves endothelial function within 1 month. Circulation. 1997:95:1126-31.

33. Davignon J. Beneficial cardiovascular pleiotropic effects of statins. Circulation. 2004;109:III39-43.

34. Arnaud C, Burger F, Steffens S, Veillard NR, Nguyen TH, Trono D, et al. Statins reduce interleukin-6-induced C-reactive protein in human hepatocytes: new evidence for direct antiinflammatory effects of statins. Arterioscler Thromb Vasc Biol. 2005;25:1231-6.

35. Kruger PS, Freir NM, Venkatesh B, Robertson TA, Roberts MS, Jones M. A preliminary study of atorvastatin plasma concentrations in critically ill patients with sepsis. Intensive Care Med. 2009;35:717-21.

\section{Submit your next manuscript to BioMed Central and take full advantage of:}

- Convenient online submission

- Thorough peer review

- No space constraints or color figure charges

- Immediate publication on acceptance

- Inclusion in PubMed, CAS, Scopus and Google Scholar

- Research which is freely available for redistribution 